\title{
Toxicity and antibacterial assessment of chitosan- coated silver nanoparticles on human pathogens and macrophage cells
}

This article was published in the following Dove Press journal:

International Journal of Nanomedicine

2 April 2012

Number of times this article has been viewed

Prajna Jena'

Soumitra Mohanty'

Rojee Mallick'

Biju Jacob ${ }^{2}$

Avinash Sonawane'

'School of Biotechnology, KIIT

University, Bhubaneswar, Orissa, India

${ }^{2}$ Center for Innovation, Technopark

Technology Business Incubator,

Bangalore, Karnataka, India
Correspondence: Avinash Sonawane

School of Biotechnology, Campus-I I, KIIT University, Bhubaneswar 751024, Orissa, India

Tel +9| 6742725349

Fax+91 6742725732

Email asonawane@kiitbiotech.ac.in
Background: Pathogenic bacteria are able to develop various strategies to counteract the bactericidal action of antibiotics. Silver nanoparticles (AgNPs) have emerged as a potential alternative to conventional antibiotics because of their potent antimicrobial properties. The purpose of this study was to synthesize chitosan-stabilized AgNPs (CS-AgNPs) and test for their cytotoxic, genotoxic, macrophage cell uptake, antibacterial, and antibiofilm activities.

Methods: AgNPs were synthesized using chitosan as both a stabilizing and a reducing agent. Antibacterial activity was determined by colony-forming unit assay and scanning electron microscopy. Genotoxic and cytotoxic activity were determined by DNA fragmentation, comet, and MTT [3-(4,5-dimethylthiazol-2-yl)-2,5-diphenyltetrazolium bromide] assays. Cellular uptake and intracellular antibacterial activity were tested on macrophages.

Results: CS-AgNPs exhibited potent antibacterial activity against different human pathogens and also impeded bacterial biofilm formation. Scanning electron microscopy analysis indicated that CS-AgNPs kill bacteria by disrupting the cell membrane. CS-AgNPs showed no significant cytotoxic or DNA damage effect on macrophages at the bactericidal dose. Propidium iodide staining indicated active endocytosis of CS-AgNPs resulting in reduced intracellular bacterial survival in macrophages.

Conclusion: The present study concludes that at a specific dose, chitosan-based AgNPs kill bacteria without harming the host cells, thus representing a potential template for the design of antibacterial agents to decrease bacterial colonization and to overcome the problem of drug resistance.

Keywords: chitosan-silver nanoparticles, antibiofilm, cytotoxicity, genotoxicity

\section{Introduction}

Bacterial infections are still a leading cause of death for millions of people worldwide. This is primarily because of the emergence of new disease agents and the development of multidrug-resistant strains. Moreover, the pathogens have evolved effective approaches to counteract the biocidal action of antibacterial molecules. As a result, even though many antibiotics have been developed, very few antibiotics have proved effective against multidrug-resistant bacteria. Therefore, it is extremely important to design and develop new antibiotics that overcome these limitations. Recently, nanoparticles have been used successfully for the delivery of therapeutic agents, ${ }^{1}$ in chronic disease diagnostics, ${ }^{2}$ to reduce bacterial infections, ${ }^{3}$ and in the food and clothing industries as an antimicrobial agent. ${ }^{4}$ Because of their potent antimicrobial activity and unique mode of action, nanoparticles offer an attractive alternative to conventional antibiotics in the development of new-generation antibiotics. Of the range of nanoparticle options available, silver nanoparticles (AgNPs) have received intensive interest because of their 
various applications in the medical field. ${ }^{5}$ Although silver has been used as an antimicrobial substance for centuries, ${ }^{6}$ it is only recently that researchers have shown unprecedented interest in this element as a therapeutic agent to overcome the problem of drug resistance caused by the abuse of antibiotics. ${ }^{7,8}$ The mechanism by which silver exerts its bioactivity is still only poorly understood. It has been reported that the mode of antibacterial action of silver ions is probably similar to that of AgNPs. ${ }^{9}$ It is generally recognized that AgNPs may attach to the microbial cell wall and thus exert a toxic effect by disturbing cell wall permeability. The nanoparticles may also penetrate the cell and affect cellular respiration through inactivating the essential enzymes by forming complexes with the catalytic sulfur of thiol groups in cysteine residues ${ }^{10}$ and through the production of toxic radicals such as superoxide, hydrogen peroxide, and hydroxyl ions. In addition to their direct bactericidal activity, nanoparticles are also known to disrupt biofilm formation. ${ }^{11}$ Biofilms are formed because of the attachment of bacteria to the solid surfaces resulting in the agglomeration of bacterial cells. Biofilms augment resistance to drug therapy and disinfectants and they help pathogens evade host immune responses and establish chronic infections. AgNPs also exhibit genotoxic and cytotoxic effects in human tissue culture, causing DNA damage, chromosome aberrations, and cell death if they are directly applied above a certain concentration level. ${ }^{12}$

To date, numerous methods concerning the fabrication of AgNPs have been developed. ${ }^{13-16}$ Among the synthetic methods, a chemical reduction of silver salt solution using reducing agents such as sodium dodecyl sulfate, citrate, ascorbate, hyperbranched polyester, $N, N$-dimethylformamide, and sodium borohydride is most commonly used. ${ }^{16-18}$ Most of these reducing agents lead to environmental toxicity or biological hazards; therefore, the trend has shifted to biological synthesis of AgNPs using polymer matrices, as they have no toxicity risks and they can be easily designed into almost any shape required for a particular application. This includes the use of different biopolymers such as starch, ${ }^{19}$ chitosan, ${ }^{6}$ cyclodextrins, ${ }^{20}$ and bacterial biomass ${ }^{21}$ that act as both a stabilizing and a reducing agent. Recently, the authors reported the synthesis of green AgNPs using the cell biomass of Cochliobolus lunatus. ${ }^{22}$ Similarly, other studies have shown that exposure of silver ions to Trichoderma viride $^{21}$ and Escherichia coli ${ }^{23}$ filtrate resulted in the reduction of silver ions and the formation of extremely stable silver particles. The use of biopolymers in nanoparticle preparation has several advantages over conventional synthetic chemical agents. Macromolecular chains of these biopolymers possess a large number of hydroxyl groups and so they can complex well with metal ions - this further enables control of size, shape, and dispersion of nanoparticles - and they are less toxic to mammalian cells.

In the present study, chitosan was used for the synthesis of stable AgNPs. Chitosan, a positively charged polysaccharide biopolymer derived from chitin, exhibits a number of interesting biological properties such as antimicrobial activity, chelating and polycationic properties, biodegradability, biocompatibility, the ability to induce disease resistance in plants, and display of stimulating or inhibiting activities toward human cells. ${ }^{24,25}$ For these reasons, chitosan has received great attention in the fields of medicine, food, chemicals, pharmaceuticals, and agriculture. ${ }^{26-29}$

Although several independent studies have shown applications of nanoparticles in various fields, studies describing their impact on counteracting bacterial infections are limited. In this study, chitosan-stabilized AgNPs (CS-AgNPs) were synthesized, characterized by transmission electron microscopy (TEM) and dynamic light scattering, and tested for antibacterial activity against a panel of human pathogens such as Staphylococcus aureus, Pseudomonas aeruginosa, Salmonella typhi, and Mycobacterium smegmatis, representing Gram-positive, Gram-negative, and acid-fast bacteria. These bacteria are known to infect humans through exposure to contaminated air, food, and water, and they are responsible for serious communicable and noncommunicable diseases. Moreover, these pathogens are posing serious problems because of the emergence of multidrug-resistant strains. In this article the authors report that CS-AgNPs exhibit potent antibacterial activity against the aforementioned human pathogens and impede biofilm formation. Single cell gel electrophoresis (comet), nucleus staining, and DNA fragmentation assays indicated that CS-AgNPs do not cause DNA damage of host cells after treatment with a bactericidal dose of nanoparticles. Moreover, macrophages actively endocytose propidium iodide (PI)-labeled CS-AgNPs, resulting in the intracellular killing of $M$. smegmatis. The combined data support the biomedical application of CSAgNPs as an antibacterial therapeutic agent.

\section{Materials and methods Bacterial strains and reagents}

$P$. aeruginosa $\mathrm{PAO} 1, S$. typhi, and $S$. aureus were grown in Luria Bertani (LB) medium at $37^{\circ} \mathrm{C}$ on a shaker (180 rpm). Chitosan, low melting point agarose, DAPI (4, 6-diamidino-2-phenylindole), and crystal violet were purchased from Sigma-Aldrich (St Louis, MO). MTT [3-(4,5-dimethylt 
hiazol-2-yl)-2,5-diphenyltetrazolium bromide] was purchased from MP Biomedicals United States (Solon, OH). Silver nitrate $\left(\mathrm{AgNO}_{3}\right)$ was obtained from Fisher Scientific (Mumbai, India). PI was purchased from Invitrogen (Carlsbad, CA). The mouse macrophage cell line RAW264.7 was cultured in Dulbecco's modified Eagle's medium (DMEM; HIMEDIA, Mumbai, India) supplemented with 10\% fetal calf serum, $1 \%$ penicillin-streptomycin solution, $1 \%$ L-glutamine and HEPES [4-(2-hydroxyethyl)-1-piperazineethanesulfonic acid].

\section{Synthesis of chitosan-based AgNPs}

High-molecular-weight chitosan ( $>75 \%$ deacetylated) was used for the synthesis of AgNPs. Chitosan solution ( $1 \mathrm{mg} / \mathrm{mL})$ was prepared in $1 \%$ acetic acid and the mixture was stirred at $45^{\circ} \mathrm{C}$ to obtain a homogeneous solution. The chitosan solution $(24 \mathrm{~mL})$ was then mixed with $0.1 \mathrm{~N}$ sodium hydroxide $(\mathrm{NaOH})$ solution $(75 \mathrm{~mL})$ and $100 \mathrm{mM} \mathrm{AgNO}$, solution $(1 \mathrm{~mL})$ was added to the resulting suspension. Change to a yellow appearance indicated the formation of AgNPs. After being allowed to settle, the suspension was washed twice with sterile distilled water $\left(\mathrm{dH}_{2} \mathrm{O}\right)$ and centrifuged at $2000 \mathrm{rpm}$ for 5 minutes. The final pellet was dried and dissolved in $0.1 \%$ acetic acid, resulting in a yield of $136 \mathrm{ppm}$. A range of CS-AgNP concentrations were used to treat the bacteria and for other experiments in this study.

\section{Quantitative determination of chitosan in CS-AgNPs}

The ninhydrin method was used for quantitative analysis of chitosan present in CS-AgNPs. ${ }^{30}$ Ninhydrin reagent was prepared by dissolving ninhydrin $(0.5 \mathrm{~g})$ in isopropanol $(30 \mathrm{~mL})$. The resulting solution was mixed with $20 \mathrm{~mL}$ of sodium acetate buffer ( $\mathrm{pH}$ 5.5). A chitosan standard curve ranging from $10 \mu \mathrm{g} / \mathrm{mL}$ to $1 \mathrm{mg} / \mathrm{mL}$ was determined, and this was used to calculate the quantity of chitosan present in freshly prepared (day 1) and old (day 30) CS-AgNPs. Ninhydrin reagent $(1 \mathrm{~mL})$ was added to test samples $(1 \mathrm{~mL})$ and boiled for 30 minutes. The solution was then cooled to $30^{\circ} \mathrm{C}$ and diluted with $50 \%$ ethanol $(5 \mathrm{~mL})$. The absorbance at $570 \mathrm{~nm}$ was measured on an ultraviolet (UV) and visible spectrophotometer (UV-1800; Shimadzu, Kyoto, Japan).

\section{Nanoparticle characterization}

UV and visible spectroscopy were used to characterize synthesized nanoparticles, with an Epoch UV-Vis spectrophotometer (BioTek Germany, Bad Friedrichshall, Germany) at a resolution of $1 \mathrm{~nm}$ from 200 to $900 \mathrm{~nm}$. For TEM analysis, a drop of aqueous solution containing the CS-AgNPs was placed on carbon-coated copper grids. The samples were dried and kept under a desiccator before then being loaded onto a specimen holder. The TEM measurements were performed on a Tecnai ${ }^{\circledR}$ G2 transmission electron microscope (FEI Company, Hillsboro, OR) operating at $200 \mathrm{kV}$. The size distribution and zeta potential of the chitosan and CS-AgNPs were determined by dynamic light scattering (Zetasizer Nano ZS; Malvern Instruments Ltd, Malvern, Worcestershire, UK).

\section{In vitro killing assay}

To determine the antibacterial activity of the CS-AgNPs, cultures grown overnight were centrifuged at $5000 \mathrm{rpm}$ for 5 minutes, washed with $1 \times$ phosphate-buffered saline $(\mathrm{PBS})$, and the final pellet suspended in LB medium. Finally, the optical density of the sample was adjusted to 0.1 at $600 \mathrm{~nm}$. Various concentrations of the CS-AgNPs were incubated with 4 or $5 \times 10^{5}$ bacteria in LB medium in 96-well roundbottom plates, and this was performed in triplicate. Bacteria were harvested at the indicated time points and the number of colony-forming units (CFUs) was assayed. All samples were plated in triplicate and values were averaged from three independent trials.

\section{Diffusion assay}

Bacterial cultures were grown overnight in LB medium and centrifuged at $5000 \mathrm{rpm}$ for 5 minutes. The final pellet was washed with $1 \times$ PBS and resuspended in LB medium. The suspended culture $(100 \mu \mathrm{L})$ was spread uniformly on LB plates and the plates were incubated at $37^{\circ} \mathrm{C}$ for 30 minutes. Different concentrations of CS-AgNPs were loaded into the wells. The zone of inhibition was determined by measuring the diameter of the zone of inhibition after 24 hours.

\section{Cytotoxic assay}

To determine the cytotoxic activity of the CS-AgNPs on macrophages, RAW264.7 cells $\left(1 \times 10^{4}\right.$ cells $\left./ \mathrm{mL}\right)$ were grown in DMEM in a 96 -well plate at $37^{\circ} \mathrm{C}$ in an atmosphere of $5 \%$ carbon dioxide $\left(\mathrm{CO}_{2}\right)$ for 24 hours, followed by treatment of the cells with different concentrations of CS-AgNPs for another 24 hours. To determine the cell viability, MTT (at a concentration of $0.1 \mathrm{mg} / \mathrm{mL}$ ) was added to the wells and incubated for 4 hours at $37^{\circ} \mathrm{C}$ in an atmosphere of $5 \% \mathrm{CO}_{2}$ in the dark. In metabolically active cells, MTT was reduced to an insoluble, dark purple formazan. The formazan crystals were dissolved in dissolving buffer (sodium dodecyl sulfate [SDS] [11 g] in $0.02 \mathrm{M}$ hydrochloric acid [HCl] [50 mL] and isopropanol $[50 \mathrm{~mL}])$. The absorbance was read at 
$570 \mathrm{~nm}$ using an enzyme-linked immunosorbent assay reader (BioTek Germany) and compared with the untreated cells, and the percentage of viable cells was calculated.

\section{DNA fragmentation assay}

The effect of CS-AgNPs on macrophage DNA fragmentation was determined as described previously. ${ }^{31}$ Briefly, RAW264.7 cells $\left(1 \times 10^{6}\right.$ cells $\left./ \mathrm{mL}\right)$ were seeded in a six-well plate and treated with different concentrations of CS-AgNPs. The cells were trypsinized at 6 hours and pelleted, and genomic DNA was isolated by the phenol-chloroform extraction method. The cell pellet was washed with PBS, lysed by the addition of lysis buffer (10 mM ethylenediaminetetraacetic acid [EDTA], $0.5 \%$ Triton $^{\circledR}$ $\mathrm{X}$-100, 5 mM Tris [2-amino-2-hydroxymethyl-propane-1,3-diol] $\mathrm{HCl}, \mathrm{pH} 8.0$ ) and incubated on ice for 30 minutes. Samples were centrifuged and the supernatant was treated with ribonuclease $\mathrm{A}$ for 1 hour, followed by digestion with proteinase $\mathrm{K}(0.5 \mathrm{mg} / \mathrm{mL})$ (Roche, Mannheim, Germany) for 3 hours at $50^{\circ} \mathrm{C}$. Phenolchloroform-isoamyl alcohol (25:24:1) extraction was performed and the DNA was precipitated with 2.5 volumes of $95 \%$ ethanol and one-tenth volume of $3 \mathrm{M}$ sodium acetate ( $\mathrm{pH}$ 5.2). DNA was dissolved and electrophoresed in $1.5 \%$ agarose gel at $40 \mathrm{~V}$. The gel was stained with ethidium bromide and DNA fragments were visualized under UV light.

\section{Cellular uptake studies}

CS-AgNPs were labeled with PI, as described previously. ${ }^{32} \mathrm{CS}-$ AgNPs dispersed in DMEM were mixed with PI $(0.1 \mu \mathrm{g} / \mathrm{mL})$ and the mixture was incubated at room temperature for 2 hours. RAW264.7 cells $\left(1 \times 10^{5}\right.$ cells $\left./ \mathrm{mL}\right)$ were grown on glass coverslips. PI-labeled nanoparticles were added to the cells and incubated for 1 hour. The cells were washed several times with $1 \times$ PBS and fixed with $3.7 \%$ paraformaldehyde for 30 minutes at $37^{\circ} \mathrm{C}$. After incubation, cells were washed with $1 \times \mathrm{PBS}$ and mounted on glass slides. The images were visualized using a fluorescence microscope (ECLIPSE-Ti; Nikon, Tokyo, Japan).

\section{Comet assay}

The alkaline comet assay was performed to check the effect of CS-AgNP treatment on DNA damage. Macrophages were treated with CS-AgNPs (3 and $20 \mathrm{ppm}$ ) for 6 hours at $37^{\circ} \mathrm{C}$ in an atmosphere of $5 \% \mathrm{CO}_{2}$. Untreated cells were used as a control. Cells were trypsinized and cell suspension $(400 \mu \mathrm{L})$ was mixed with $1 \%$ low melting point agarose $(1 \mathrm{~mL})$. The mixture was added to glass cavity slides (Blue Label Scientifics Pvt Ltd, Mumbai, India). The agarose was allowed to solidify and then the slides were submerged in lysis solution (1.2 M sodium chloride, $100 \mathrm{mM}$ EDTA disodium salt, $0.1 \%$
$\mathrm{SDS}, 0.26 \mathrm{M} \mathrm{NaOH}[\mathrm{pH}>13]$ ) for 2 hours at $4^{\circ} \mathrm{C}$ in the dark. After lysis, the slides were washed with $\mathrm{dH}_{2} \mathrm{O}$, transferred to an electrophoresis unit, covered with freshly prepared electrophoresis buffer $(0.03 \mathrm{M} \mathrm{NaOH}, 2 \mathrm{mM}$ EDTA disodium salt [pH 12.3]), left for unwinding of DNA for 30 minutes, and the cells were electrophoresed for 20 minutes at $22 \mathrm{~V}$ and $200 \mathrm{~mA}$. The cells were neutralized with neutralization buffer $(500 \mathrm{mM}$ Tris $\mathrm{HCl}, \mathrm{pH} 8.0$ ) for 15 minutes, washed 3-4 times with $\mathrm{dH}_{2} \mathrm{O}$, and stained with PI ( $4 \mu \mathrm{g} / \mathrm{mL})$ for 1 hour. The slides were dried and then observed using the fluorescence microscope.

\section{Effect on intracellular killing of M. smegmatis}

To examine whether treatment with CS-AgNPs increases the killing efficiency of macrophages, $5 \times 10^{5}$ RAW264.7 cells were treated with AgNPs ( $3 \mathrm{ppm}$ ) 1 hour before Mycobacterium smegmatis infection - referred to as "pretreated," whereas in "post-treated" conditions macrophages were treated with the same concentration of CS-AgNPs but 1 hour post infection. Pretreated cells were washed with PBS, and fresh media without the AgNPs was added to the wells prior to infection. Untreated, pretreated, and post-treated cells were exposed to M. smegmatis at a multiplicity of infection of 10 for 1 hour, and extracellular bacteria were killed by the addition of gentamicin $(20 \mu \mathrm{g} / \mathrm{mL})$. Macrophages treated with chitosan alone were used as a control. After the incubation period, cells were washed and lysed with $0.5 \%$ Triton X-100; intracellular survival was estimated by plating serially diluted cultures on $7 \mathrm{H} 10$ plates and the colonies were enumerated after 72 hours.

\section{Biofilm assay}

Cultures grown overnight were diluted 1:100 in fresh LB medium. Diluted culture $(2 \mu \mathrm{L})$ was added to the 96 -well microtiter plate and incubated at $37^{\circ} \mathrm{C}$ for 24 hours without shaking. The wells were then washed with $1 \times$ PBS to remove unbound cells. Different concentrations of CS-AgNPs were added to the wells and incubated at $37^{\circ} \mathrm{C}$ for 24 hours. Thereafter, the medium was removed and the wells were thoroughly washed with $1 \times$ PBS, and $0.1 \%(w / v)$ crystal violet $(100 \mu \mathrm{L})$ was added and incubated for 20 minutes. The crystal violet was removed and washed thoroughly with $1 \times$ PBS. For quantification of attached cells the crystal violet was solubilized in absolute ethanol and the absorbance was measured at $575 \mathrm{~nm}$. Reduction of the biofilm was compared with the untreated cells.

\section{Statistical analysis}

Statistically significant differences among groups were determined using the Student's $t$-test (two-tailed, equal variances). 


\section{Results}

\section{Characterization of chitosan-coated AgNPs}

$\mathrm{AgNO}_{3}$ was reduced and stabilized with chitosan, and the UV and visible spectroscopy absorption spectrum of the resulting solution was measured. It is clear that the spectra displayed the characteristics of absorption at about $420 \mathrm{~nm}$ - a typical band for AgNPs (Figure 1A). The stability of the prepared solution was also determined by measuring its absorption spectrum at 24-hour intervals over 30 days. No significant changes in the absorbance were observed during the storage, indicating that the AgNPs did not agglomerate and they were stable during this period (Figure 1A). The amount of chitosan leached from the freshly prepared (day 1) and old (day 30) CS-AgNPs was determined by the ninhydrin method. The amount of chitosan present in the medium at days 1 and 30 was measured as 987.27 and $813.63 \mu \mathrm{g} / \mathrm{mL}$, respectively (data not shown). The shape of the CS-AgNPs was determined by TEM. A typical TEM micrograph showed spherical CS-AgNPs (Figure 1B). Dynamic light scattering showed predominantly two sizes of CS-AgNPs: 55 and $278 \mathrm{~nm}$ (Figure 1C). Surface zeta potential of chitosan and CS-AgNPs was measured as 36.3 and $51.1 \mathrm{mV}$, respectively (Figure 1D).

\section{Antibacterial activity of chitosan-AgNP composites}

The antibacterial activity of the CS-AgNPs against $S$. aureus, P. aeruginosa, S. typhi, and M. smegmatis was tested in 96-well round-bottom plates by CFU assay. Exponentially grown bacteria were incubated with different concentrations

\section{A}

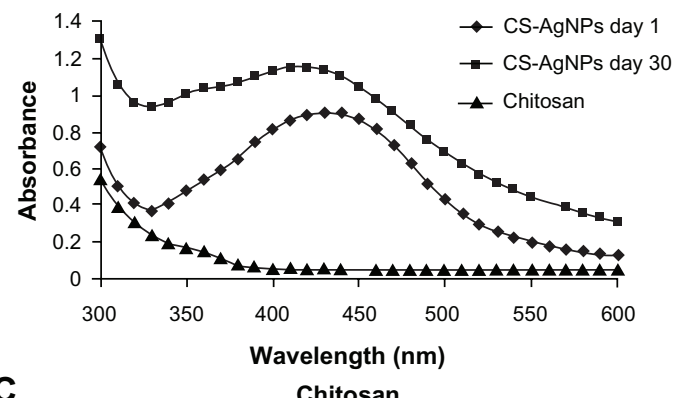

C

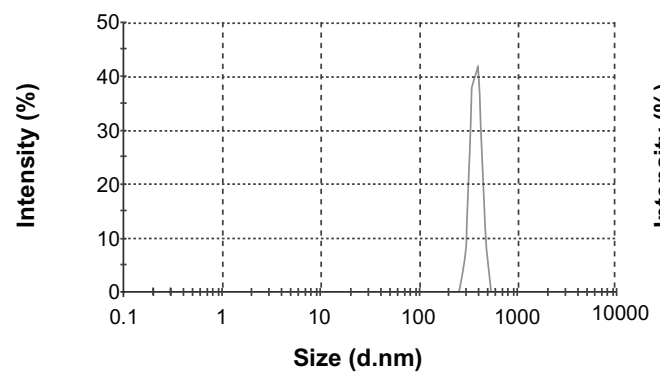

D

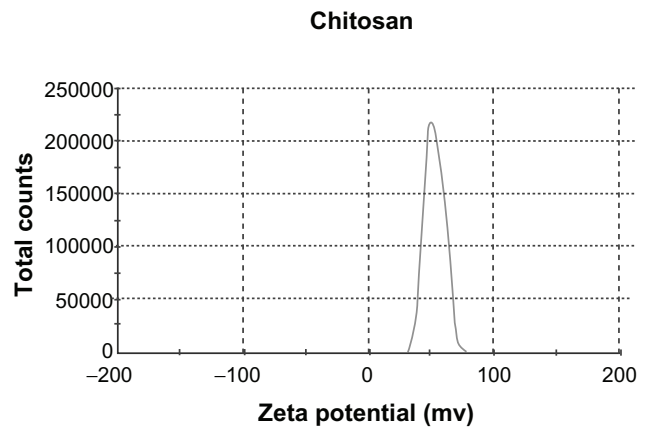

B

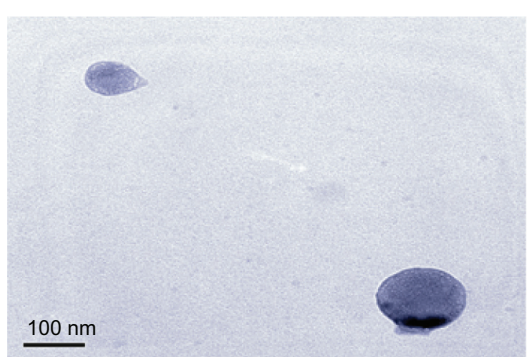

CS-AgNPs

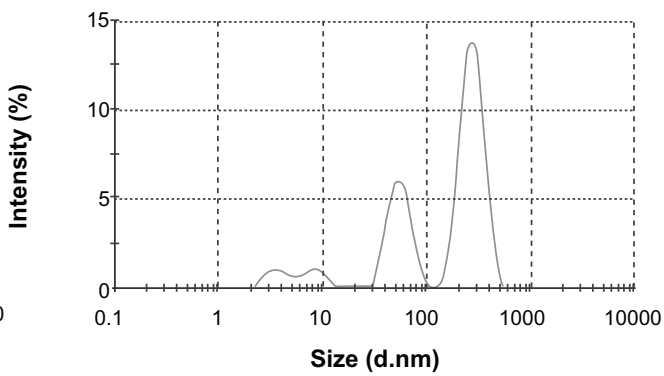

CS-AgNPs

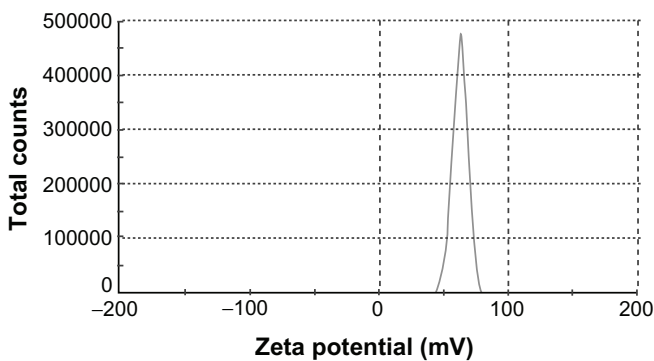

Figure I (A) Ultraviolet and visible spectroscopy absorption spectrum of the chitosan-stabilized silver nanoparticles (CS-AgNPs) (maximum absorbance at 420 nm); (B) transmission electron microscopy image of CS-AgNPs (scale bar, $100 \mathrm{~nm}$ ); (C) size distribution and (D) zeta potential of chitosan and CS-AgNPs determined by dynamic light scattering. 
of CS-AgNPs, and the number of CFUs was analyzed through harvesting bacteria at different time points by plating serial dilutions on LB plates. The surviving colonies were enumerated after 24 hours for all bacteria except M. smegmatis, in which the colonies were enumerated after 72 hours. The results were compared with bacteria grown in LB medium (control) and the reaction mixture containing all the components except $\mathrm{AgNO}_{3}$ (chitosan). The control and the corresponding concentration of chitosan statistically showed no antibacterial activity over the span of the study (Figure 2), suggesting no toxicity. In comparison, CS-AgNPs showed significant inhibitory activity toward P. aeruginosa, S. typhi, and $S$. aureus in a dose-dependent manner. As shown in Figure 2 (A-C), CS-AgNPs significantly inhibited the growth of the aforementioned strains. After 1 hour of exposure to CS-AgNPs at 1 and $2 \mathrm{ppm}$, more than $60 \%$ and $75 \%$, respectively, of the bacteria were killed, whereas after 4 hours of incubation more than $95 \%$ killing was observed, relative to the control and chitosan. In comparison, M. smegmatis was found to be less susceptible
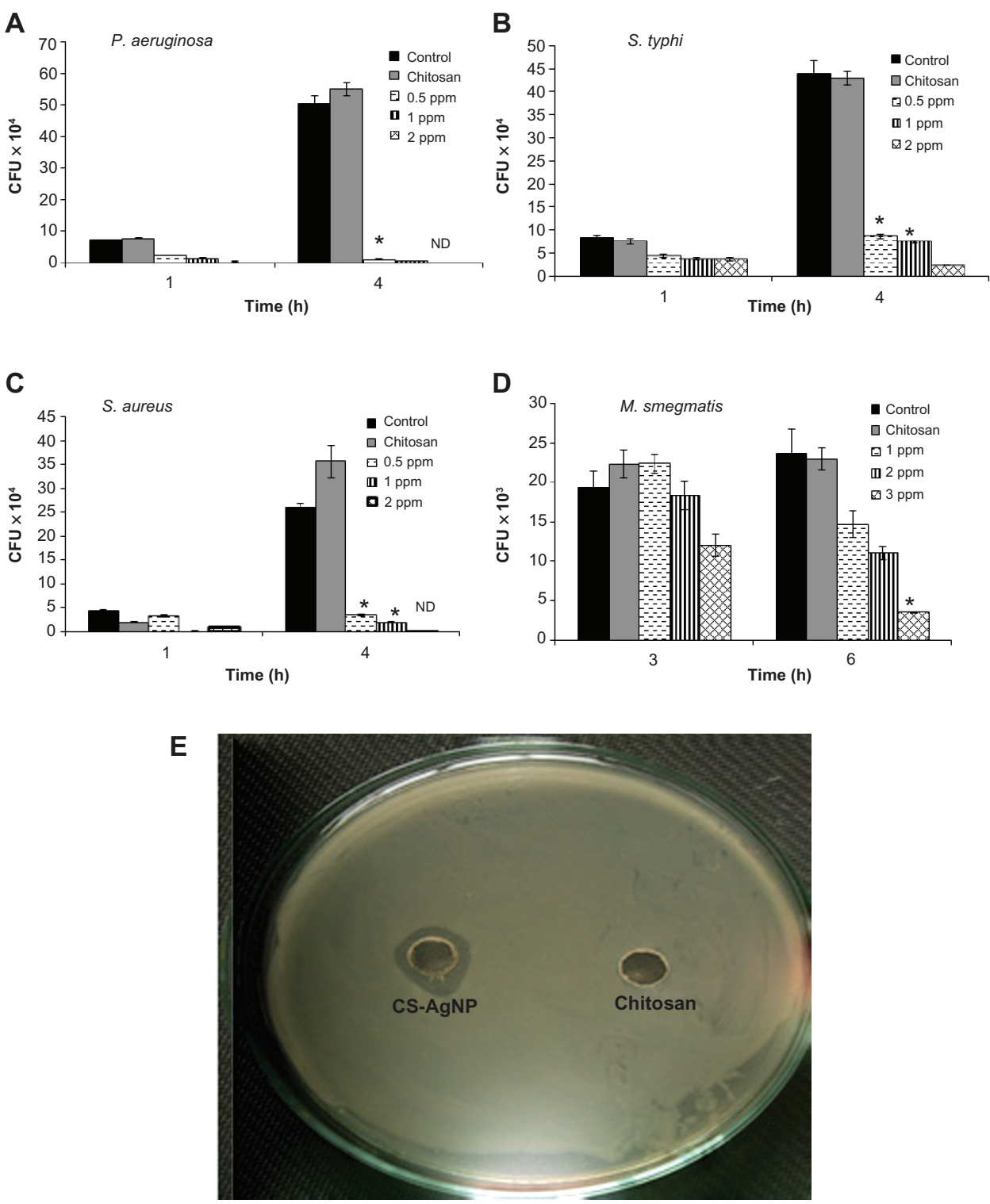

Figure 2 Dose-dependent killing of bacterial strains by chitosan-stabilized silver nanoparticles (CS-AgNPs): (A) Pseudomonas aeruginosa, (B) Salmonella typhi, (C) Staphylococcus aureus, and (D) Mycobacterium smegmatis were incubated with different concentrations of CS-AgNPs. Bacterial survival was determined at I and 4 hours by colony-forming unit (CFU) assay. Media containing bacteria alone (control) and chitosan plus bacteria (chitosan) were used as controls. (E) Antibacterial activity of CS-AgNPs by diffusion method: CS-AgNPs at 100 ppm $(20 \mu \mathrm{L})$ were loaded into wells formed on plates containing a lawn of $P$. aeruginosa; growth inhibition was determined by measuring the zone of inhibition after 24 hours; chitosan was used as a control.

Notes: Experiments were performed in triplicate; results are shown as mean plus or minus standard deviation; $* P \leq 0.05$.

Abbreviation: ND, bacterial growth not detected. 
to the inhibitory effect of CS-AgNPs, such that $5 \%$ and $37 \%$ of the bacteria were killed at 2 and 3 ppm after 3 hours' incubation, but no killing was observed at 1 ppm. However, the loss of $M$. smegmatis viability steadily increased with extending incubation time, such that more than $50 \%$ and $85 \%$ bacteria were killed at 2 and 3 ppm, respectively, after 6 hours' incubation (Figure 2D).

The bactericidal activity observed under in vitro conditions was also demonstrated by the zone inhibition method - a qualitative method for measuring the antibacterial action. Following this method, CS-AgNPs were applied into a well formed on the Luria-Bertani (LB) agar plate (HIMEDIA) containing approximately $10^{6} \mathrm{CFU} / \mathrm{mL}$ of the bacteria. After 24 hours of incubation, a plate loaded with CS-AgNPs $(20 \mu \mathrm{L})$ showed a clear zone of inhibition of approximately $14 \mathrm{~mm}$ in diameter, while the plate loaded with all reaction components except $\mathrm{AgNO}_{3}$ (chitosan) showed a dense population of bacteria. Figure 2E shows a representative plate displaying the zone of inhibition of $P$. aeruginosa. Similar results were obtained with S. aureus (Figure S1).

\section{Destruction of bacterial membrane}

To find out how chitosan-based AgNPs kill bacteria, scanning electron microscopy was used to illustrate interactions between CS-AgNPs and $P$. aeruginosa cells. Figure 3 shows how the $P$. aeruginosa cells lost their cellular integrity after exposure to CS-AgNPs at a concentration of 2 ppm, whereas untreated and chitosan-treated cells remained intact. Also, the authors observed that CS-AgNP treatment resulted in the formation of large aggregates.

\section{Effect on biofilm formation}

Biofilms limit the diffusion of drug molecules and contribute to the pathogenesis of infection; therefore, the inhibition of biofilm formation is important to prevent bacterial colonization and to increase the susceptibility to the administered drug. Among the bacteria tested in this study, P. aeruginosa and $S$. aureus are known for their ability to form biofilms by adhering to a surface and coating it with slime. The authors determined if treatment with CS-AgNPs inhibited this biofilm formation and/or disrupted the preformed biofilms under in vitro conditions by monitoring the binding of the dye crystal violet to adherent cells that directly reflected effective ability in biofilm formation. To determine the effect on disruption of preformed biofilms, $P$. aeruginosa and $S$. aureus were allowed to form biofilms for 24 hours in a 96-well microtiter plate and were then treated with varying concentrations of CS-AgNPs; to study the inhibitory effect, CS-AgNPs were added to the bacterial cultures before the biofilms were formed. No significant effect on the disruption of preformed biofilms was observed (data not shown). In contrast, early exposure of $P$. aeruginosa to CS-AgNPs significantly inhibited the formation of biofilm. Treatment for 24 hours with CS-AgNPs at 2 ppm decreased more than $65 \%$ of the biofilms formed; however, the effect was limited, as no further increase in biofilm inhibition was observed with increase in nanoparticle concentration (Figure 4A). In comparison, treatment of $S$. aureus with the same concentration (2 ppm) showed no significant reduction $(22 \%$ inhibition); however, treatment with a higher dose (5 ppm) resulted in $65 \%$ inhibition of biofilm formation (Figure 4B).

\section{Cytotoxic effect}

Despite their potent antibacterial activity and wide range of biomedical applications, the use of AgNPs as therapeutic agents is limited because of their cytotoxicity against mammalian cells. It is known that the biopolymer coating of AgNPs can exert the antimicrobial activity of AgNPs, but it has no cytotoxic effect on mammalian cells, because of the slow release of silver ions from the gel matrix. As the majority of pathogens used in this study infect macrophages,
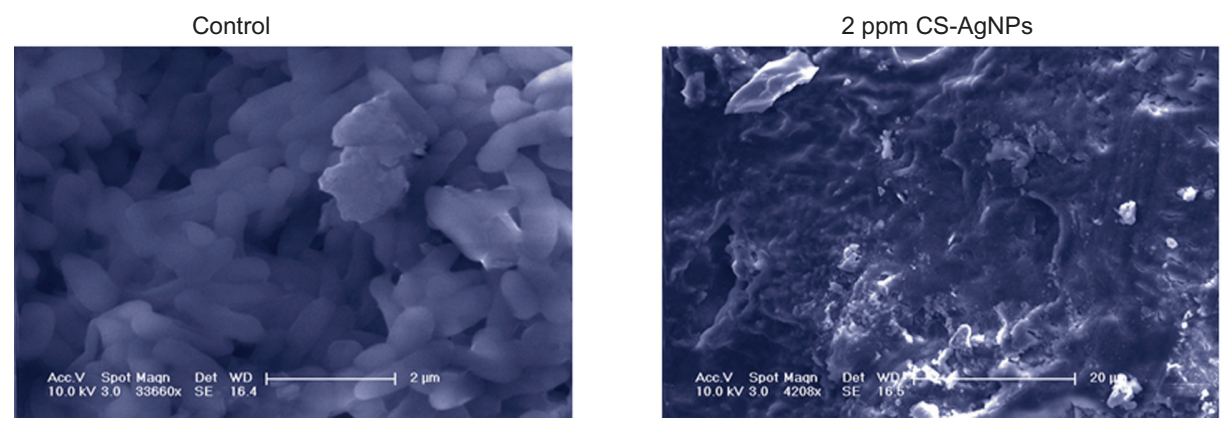

Figure 3 Scanning electron microscopy images of Pseudomonas aeruginosa after incubation with medium (control) and chitosan-stabilized silver nanoparticles (CS-AgNPs) (2 ppm) for 4 hours.

Note: Scanning electron microscopy analysis was performed on a SUI5I0 scanning electron microscope (Hitachi, Tokyo, Japan). 

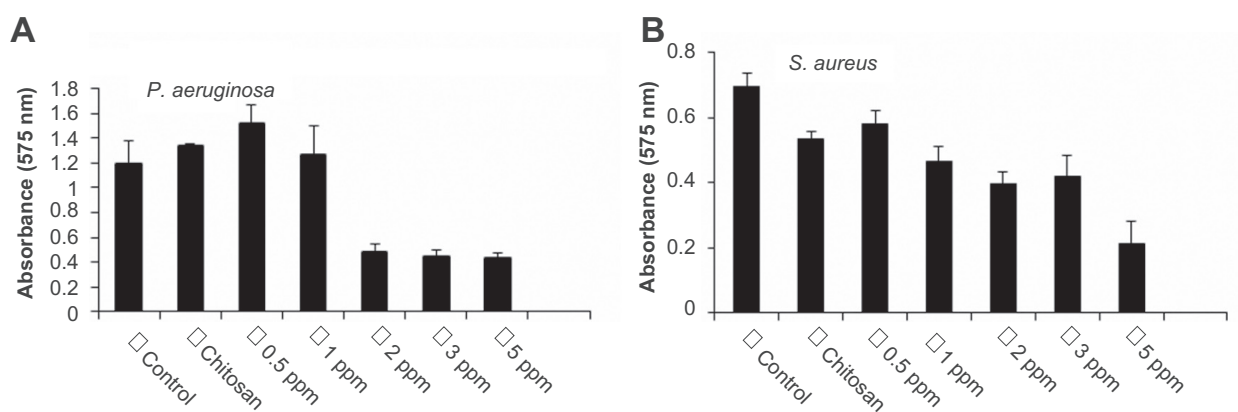

Figure 4 Effect of chitosan-stabilized silver nanoparticles (CS-AgNPs) on biofilm formation: the antibiofilm activity of CS-AgNPs was checked by incubating (A) Pseudomonas aeruginosa and (B) Staphylococcus aureus with different concentrations of CS-AgNPs for 24 hours in a 96-well plate. The addition of increasing concentrations of CS-AgNPs reduced the ability of the organisms to form biofilms.

Notes: Experiments were performed in triplicate; results are shown as mean plus or minus standard deviation.

the authors used the MTT assay to test the cytotoxicity in macrophages treated with CS-AgNPs. MTT assay relies on the fact that metabolically active cells reduce MTT to purple formazan; hence, the intensity of dye read at $570 \mathrm{~nm}$ is directly proportional to the number of viable cells. The cytotoxicity assay showed a concentration-dependent drop in cell viability (Figure 5). The cell viability was not significantly affected at 24 hours of incubation in the presence of $3 \mathrm{ppm}$, a dose that was found to be lethal for the bacteria tested in this study. Cell viability dropped drastically at the nanoparticle concentration of $10 \mathrm{ppm}$. When chitosan alone was used as a control, it showed no cytotoxicity. The authors also examined the macrophage cell morphology in a monolayer culture after the treatment with varying concentrations of CS-AgNPs. Microscopic observations showed no distinct morphological changes in the cells treated with a bactericidal dose (2 ppm) of CS-AgNPs, indicating healthy cells (Figure S2). However, in agreement with the cytotoxicity results, treatment with nanoparticles at $10 \mathrm{ppm}$ showed distinct morphological changes. The cells appeared to be clustered, and the cellspreading patterns were restricted compared with the patterns of control cells.

\section{Genotoxicity of CS-AgNPs}

Various studies have shown that higher doses of nanoparticles mediate cell death by various mechanisms such as inducing apoptosis, DNA fragmentation, and DNA damage. In this study, the authors determined the DNA fragmentation and DNA damage in macrophages at the bactericidal and higher doses of CS-AgNPs. No laddering patterns were observed in the gel in control macrophages or those treated with CS-AgNPs at 3 ppm, whereas a higher dose of CS-AgNPs (10 ppm) showed a distinct ladder pattern after 6 hours of treatment (Figure 6A).

Chromosome abnormalities such as double-strand breaks are a direct consequence of DNA damage. DNA damage by CS-AgNPs was further studied using the comet assay. In this assay, the length of the tail increases with the extent of

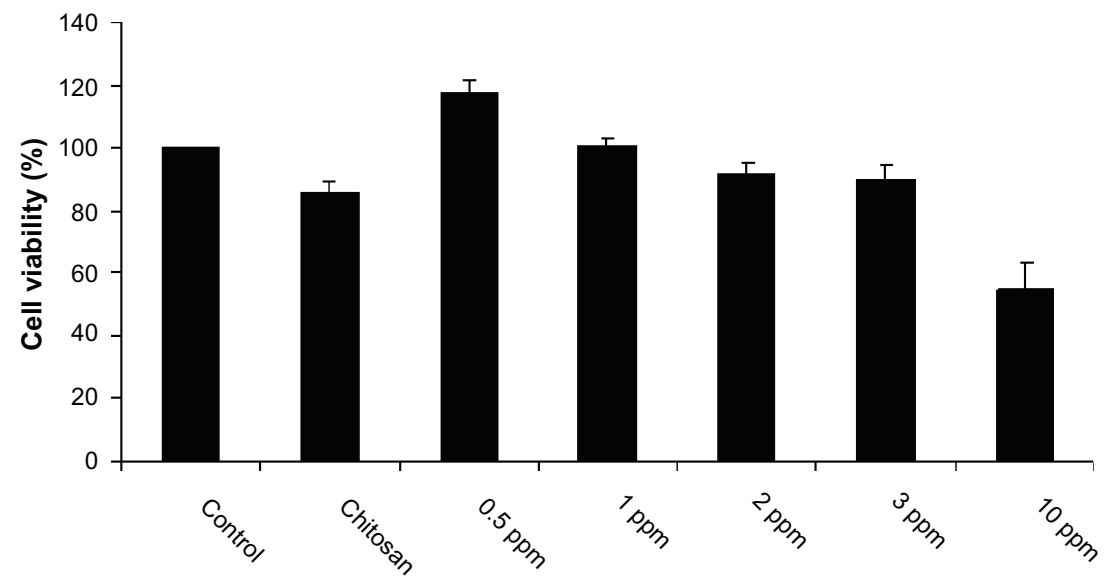

Figure 5 Cytotoxic activity of chitosan-stabilized silver nanoparticles (CS-AgNPs) on mouse macrophage RAW264.7 cells. Macrophages were treated with different concentrations of CS-AgNPs for 24 hours; cell viability was determined by MTT [3-(4,5-dimethylthiazol-2-yl)-2,5-diphenyltetrazolium bromide] assay. Notes: Experiments were performed in triplicate; results are shown as mean plus or minus standard deviation. 


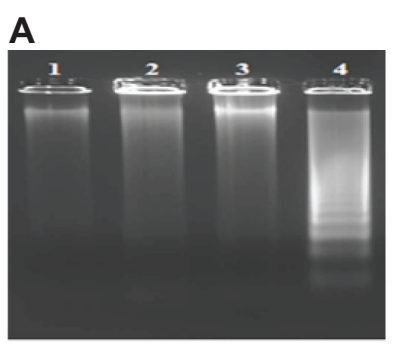

B Control

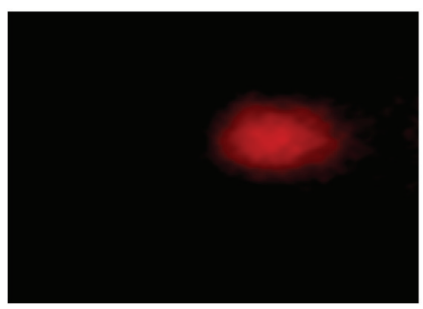

C

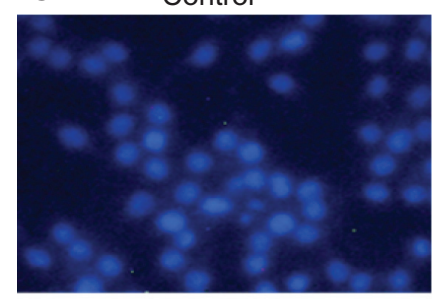

$3 \mathrm{ppm}$

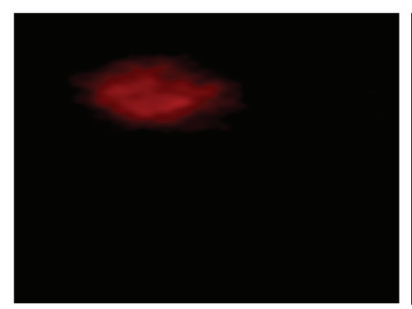

$3 \mathrm{ppm}$

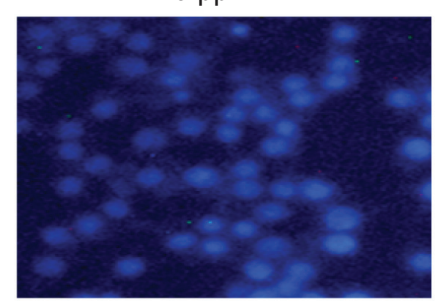

$20 \mathrm{ppm}$

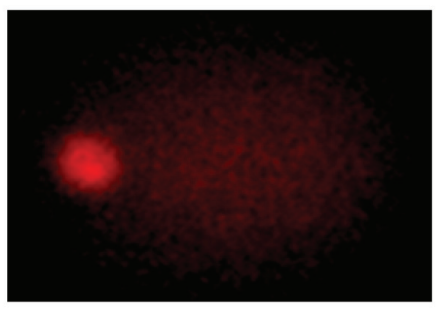

$10 \mathrm{ppm}$

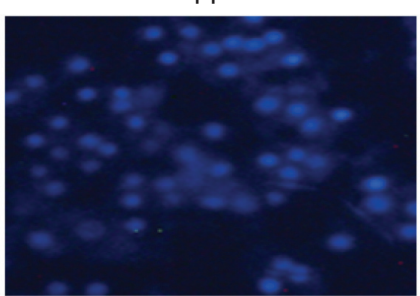

Figure 6 Genotoxic activity of chitosan-stabilized silver nanoparticles (CS-AgNPs) on mouse macrophage RAW264.7 cells: (A) DNA fragmentation of macrophages treated with different concentrations of CS-AgNPs for 6 hours - DNA was isolated from untreated (lane I), chitosan (lane 2), and CS-AgNP-treated (3 and I0 ppm, lanes 3 and 4 , respectively) macrophages and electrophoresed on agarose gel; (B) comet analysis - control and CS-AgNP-treated (3 and 20 ppm) macrophages stained with propidium iodide ( $4 \mu \mathrm{g} / \mathrm{mL})$; (C) DAPI (4, 6-diamidino-2-phenylindole) staining of control and CS-AgNP-treated (3 and 10 ppm) macrophages.

DNA damage. Tail length of control DNA was compared with that of nanoparticle-treated cells, and the extent of damage was assessed. Cells treated with CS-AgNPs showed a concentration-dependent increase in tail length as compared with control cells. No significant DNA damage was observed in control cells or cells treated with CS-AgNP at 3 ppm, whereas a comet-like tail, which implies DNA damage, was observed at the concentration of 20 ppm (Figure 6B). This observation was further supported by DAPI staining of the nucleus. As shown in Figure 6C, no significant changes in the nuclear morphology were observed at the concentration of $3 \mathrm{ppm}$. In contrast, nucleus shrinkage was observed in the macrophages treated with CS-AgNPs at $10 \mathrm{ppm}$.

\section{Intracellular bacterial killing}

Macrophages are professional phagocytic cells that can internalize particles up to $10 \mu \mathrm{m}$ in size. The authors hypothesized that exogenous addition of CS-AgNPs may lead to endocytosis of CS-AgNPs by macrophages, resulting in intracellular killing of bacteria. Fluorescent microscopy was used to determine if PI-labeled particles were internalized by macrophages. Particle internalization was compared with free PI under identical conditions. The free PI showed minimal dye internalization but the macrophages showed active endocytosis of fluorescently labeled CS-AgNPs (Figure 7A).

The infection conditions and intracellular survival kinetics of $M$. smegmatis have been well characterized in macrophages. ${ }^{33}$ For this reason the authors chose these two models to evaluate the killing activity of M. smegmatisinfected macrophages after treatment with CS-AgNPs. Macrophages were treated with CS-AgNPs (3 ppm) 1 hour before (pretreatment) and 1 hour after (post-treatment) $M$. smegmatis infection. As shown, this concentration of nanoparticles was found to be nontoxic to the macrophages (Figure 5). As shown in Figure 7B, increased dose-dependent reduction in intracellular bacterial survival was observed at 6 hours in cells pretreated with CS-AgNPs, as compared with untreated and post-treated macrophages. Treatment with CS-AgNPs had no effect on the phagocytosis rate of bacteria (data not shown) when compared with untreated macrophages. 
A
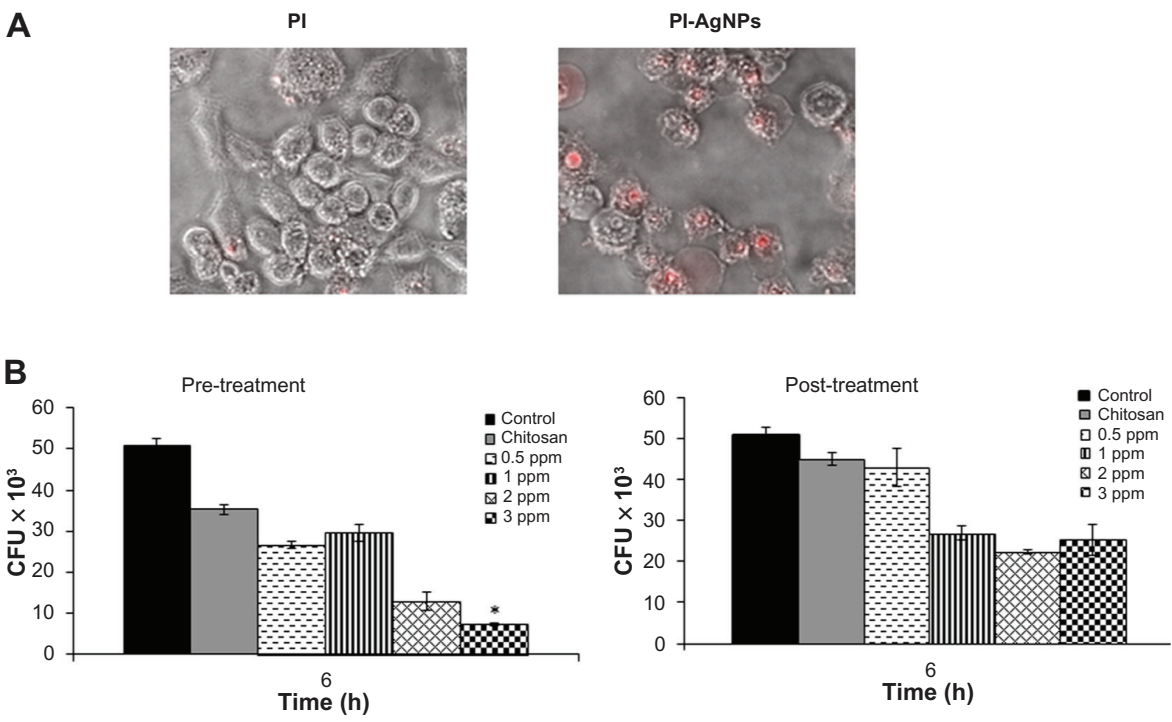

Figure 7 Chitosan-stabilized silver nanoparticles (CS-AgNPs) exhibit intracellular killing activity against Mycobacterium smegmatis. (A) Cellular uptake of propidium (PI)labeled CS-AgNPs; (B) RAW264.7 macrophages were incubated with different concentrations of CS-AgNPs for I hour before (pretreatment) and after (post-treatment) M. smegmatis infection. Macrophages infected with bacteria alone were used as a control. The cells were lysed 6 hours post infection and bacterial intracellular survival was determined by colony-forming unit (CFU) assay.

Notes: Experiments were performed in triplicate; results are shown as mean plus or minus standard deviation; $* P<0.05$

\section{Discussion}

Pathogenic microorganisms adapt various strategies to counteract the effect of the anti-infective agent and establish the infection successfully. Therefore, it is important to design more effective therapeutic strategies, including new antibiotics to overcome these challenges. In recent times nanoparticles have received a great deal of attention as a therapeutic agent because of their wide range of bioactivities and unique mode of action. In this study, the authors have shown that a specific dose of CS-AgNPs can kill the bacteria without harming the host cells. It was shown that chitosan alone has antibacterial activity, which is dependent on a number of factors such as the chitosan molecular weight; the viscosity, ionic strength, $\mathrm{pH}$, and presence of metallic ions in the medium; the temperature; and the concentration of chitosan in composite preparations. ${ }^{34,35}$ The authors first determined a concentration of chitosan, which itself would not inhibit the bacterial growth and which was suitable for the preparation of bioactive nanoparticles. Chitosan binds to metal ions because of the presence of amine and hydroxyl groups. ${ }^{36}$ Under certain conditions chitosan can reduce silver ions to AgNPs, ${ }^{37}$ which become attached to the coating polymer and thus provide stability to the AgNPs. These CS-AgNPs are spherical and they are stable for a longer duration, as determined by UV-visible absorption spectra and TEM studies (Figure 1). As previously noted, the long-term stability of AgNPs in solution is an important goal to be reached.
In order to study the antibacterial activity of CS-AgNPs, killing kinetic assays were performed with different human pathogens. The present study showed distinct differences in the susceptibility of bacteria to CS-AgNPs. P. aeruginosa, $S$. typhi, and $S$. aureus were found to be more susceptible to the action of CS-AgNPs. In contrast, the inhibitory effect of nanoparticles was moderate in M. smegmatis. This discrepancy may be due to differences in the membrane structure and the composition of the cell wall. The cell membrane of Gram-positive and Gram-negative bacteria has an overall negative charge because of the presence of teichoic acids and lipopolysaccharide (LPS), respectively. As chitosan is a cationic polymer, the potent bactericidal activity of CS-AgNPs against P. aeruginosa, S. typhi, and $S$. aureus could be because of strong interaction between cationic chitosan and the negatively charged molecules. In contrast, the mycobacteria cell wall is rich in lipids such as mycolic acids and this limits the binding and permeability of drug molecules. To study the mechanism by which CSAgNPs inactivate bacterial cells, the effect on cell integrity was evaluated by scanning electron microscopy. The results obtained indicated that irreversible damage could be induced on bacterial cells after direct contact with CS-AgNPs. The damage to the cell may be caused by interactions of AgNPs with phosphorous- and sulfur-containing compounds. Silver ions tend to have a high affinity for such molecules. ${ }^{38}$

Both P. aeruginosa and $S$. aureus are known to synthesize exopolysaccharides, protecting the bacteria from the host 
defense mechanisms. The antibiofilm activity could be due to inhibition of exopolysaccharide synthesis, because it has been shown that AgNPs impair exopolysaccharide synthesis in $P$. aeruginosa, limiting the formation of biofilm. ${ }^{12}$ In comparison, the inhibition of biofilm formation was more potent in $P$. aeruginosa. This distinction could be because of the presence of abundant LPS, which leads to strong interaction with CS-AgNPs, produced by $P$. aeruginosa. It is known that $P$. aeruginosa cells synthesize more LPS than $S$. aureus. The inhibitory effect could also be due to diffusion of CS-AgNPs through the channels present in the biofilms, which may then impart antimicrobial functions. Altogether, these results indicate that chitosan-based AgNPs not only exhibit potent bactericidal activity but also impede the formation of biofilm.

An important aspect for any molecule to be used as a therapeutic agent is that the molecule should eliminate the target without affecting the viability of mammalian cells. Many medically relevant nanoparticles such as gold and silver have been investigated for their cytotoxic effect, but different researchers have reported varying effects for these nanoparticles on mammalian cells. These differences have been largely attributed to individual AgNP preparation methodologies and target cells. Gold nanoparticles showed no significant toxicity in HeLa cells, ${ }^{39,40}$ while significant size-dependent toxicity was observed in fibroblasts, epithelial cells, and melanoma cells. ${ }^{41}$ AgNPs that did not contain any surface modifiers or stabilizers have been shown to have a significant cytotoxic effect on mouse macrophage J774.A1 cells, ${ }^{42}$ whereas starch-capped AgNPs have been shown to have no effect on cancer cells U251 and fibroblasts IMR-90 because of the slow release of silver ions from the gel matrix. ${ }^{43}$ In this study the cytotoxic effect on mouse macrophage cell line RAW264.7 was analyzed and CS-AgNPs were found to have no cytotoxic effect at the bactericidal dose after 24 hours. When chitosan alone was used as a control, it showed no significant cytotoxicity in macrophages. This observation indicates biocompatibility of chitosan as a capping agent in nanoparticles. Microscopic observations of macrophages treated with the bactericidal dose of nanoparticles did not show distinct changes when compared with control cells, whereas treatment with a high dose (10 ppm) showed abnormal morphology and few cellular extensions. This could be because of disturbances in cytoskeletal function as a result of nanoparticle treatment. Similar results were obtained with U251 and dermal fibroblast cells treated with starch-capped AgNPs and citrate-coated gold particles. ${ }^{43,44}$ Furthermore, the comet and DNA fragmentation assays showed no significant
DNA damage at the bactericidal dose, whereas treatment with a higher dose of CS-AgNPs showed increase in tail length, which signifies DNA damage, and a DNA ladder pattern. The presence of AgNPs induces formation of reactive oxygen species, which is considered to be the major source of DNA damage. Reactive oxygen species-mediated genotoxicity has been previously observed for metal oxide nanoparticles and starch-capped AgNPs. ${ }^{43,45}$ Further damage may occur from interaction of silver ions with DNA, which causes changes in the conformation of DNA. Altogether, these results indicate that CS-AgNPs have no cytotoxic or genotoxic effect on macrophages at the bactericidal dose, but they cause toxic effects when applied above a certain concentration level.

Macrophages can internalize any particle ranging up to $10 \mu \mathrm{m}$ in size. ${ }^{46}$ Previous studies have shown that latex beads and antimicrobial peptides target the macrophage phagosomes, resulting in increased maturation of phagosomes ${ }^{46}$ and intracellular killing of $S$. aureus, ${ }^{47}$ respectively. The authors also observed active uptake of PI-labeled CS-AgNPs by macrophages. The increase in intracellular killing of M. smegmatis could be because of the delivery of endocytosed AgNPs to macrophage phagosomes where $M$. smegmatis resides; alternatively, it could be because of the activation of macrophages, as treatment with AgNPs upregulate the expression of proinflammatory genes such as interleukin-1, interleukin-6, and tumor necrosis factor-alpha. ${ }^{42}$ These cytokines activate the cells, resulting in an increase in the killing efficiency of macrophages.

\section{Conclusion}

The antibacterial activities ofCS-AgNPs against $M$. smegmatis, P. aeruginosa, S. typhi, and S. aureus were compared. CFU assay results showed that CS-AgNPs exhibit potent antibacterial activities against Gram-positive and Gramnegative bacteria, followed by acid-fast $M$. smegmatis. The antibacterial activities are time and concentration dependent. Most of the bacterial killing happened in the first hour of incubation, and the bacteria kill rate increased continuously with the increase in incubation time and nanomaterial concentration. The bacterial death may be attributed to cell membrane disruption or inactivation of thiol-containing proteins. The biofilm assay results showed that CS-AgNPs exhibit potent antibiofilm activity against $P$. aeruginosa, whereas treatment of $S$. aureus with the same concentration showed no significant inhibition in biofilm formation. The MTT and cell morphology analysis results showed that CS-AgNPs exhibit no discernible cytotoxic effect on 
macrophages at the bactericidal concentration. In contrast, treatment with higher doses caused significant decrease in cell viability. The genotoxic approach was employed to elucidate the involvement of CS-AgNPs in DNA damage and DNA fragmentation. The results indicated no significant DNA damage or fragmentation at the bactericidal dose, whereas treatment with a higher concentration set off DNA damage and nucleus shrinkage, as determined by comet assay and DAPI staining. The results from this research also indicated that PIlabeled CS-AgNPs are actively endocytosed by macrophages, which leads to intracellular killing of M. smegmatis. The present study concludes that chitosan-based AgNPs exhibit potent antibacterial and antibiofilm activity, they do not exhibit cytotoxic or genotoxic effects on macrophages at the bactericidal concentration, and they kill mycobacteria residing inside the macrophages. Therefore, CS-AgNPs represent a potential template for the design of antibacterial agents to decrease bacterial colonization and to overcome the problem of drug resistance.

\section{Acknowledgments}

This work was supported by a grant (BT/PR13488/ GBD/27/270/2010) from the Department of Biotechnology, Government of India, to AS. The authors thank Dr Sanjeeb Sahoo and Malvern Instruments Ltd for providing dynamic light scattering and zeta potential analysis. The authors also thank Dr Biplab Sarkar for excellent discussions and for his help in the transmission electron microscopy studies. Finally, the authors are grateful to the Sonawane lab members for their fruitful discussions and suggestions.

\section{Disclosure}

The authors report no conflicts of interest in this work.

\section{References}

1. Zhang L, Gu FX, Chan JM, Wang AZ, Langer RS, Farokhzad OC. Nanoparticles in medicine: therapeutic applications and developments. Clin Pharmacol Ther. 2008;83(5):761-769.

2. Hong B, Kai J, Ren Y, et al. Highly sensitive rapid, reliable, and automatic cardiovascular disease diagnosis with nanoparticle fluorescence enhancer and mems. Adv Exp Med Biol. 2008;614:265-273.

3. Rai M, Yadav A, Gade A. Silver nanoparticles as a new generation of antimicrobials. Biotechnol Adv. 2009;27(1):76-83.

4. Vigneshwaran N, Kathe AA, Varadarajan PV, Nachane RP, Balasubramanya RH. Functional finishing of cotton fabrics using silver nanoparticles. J Nanosci Nanotechnol. 2007;7(6):1893-1897.

5. Castellano JJ, Shafii SM, Ko F, et al. Comparative evaluation of silver-containing antimicrobial dressings and drugs. Int Wound J. 2007;4(2):114-122.

6. Wei D, Sun W, Qian W, Ye Y, Ma X. The synthesis of chitosan-based silver nanoparticles and their antibacterial activity. Carbohydrate Research. 2009;344(17):2375-2382.
7. Panacek A, Kvitek L, Prucek R, et al. Silver colloid nanoparticles: synthesis, characterization, and their antibacterial activity. J Phys Chem B. 2006;110(33):16248-16253.

8. Sambhy V, MacBride MM, Peterson BR, Sen A. Silver bromide nanoparticle/polymer composites: dual action tunable antimicrobial materials. J Am Chem Soc. 2006;128(30):9798-9808.

9. Kong H, Jang J. Antibacterial properties of novel poly(methyl methacrylate) nanofiber containing silver nanoparticles. Langmuir. 2008;24(5):2051-2056.

10. Feng QL, Wu J, Chen GQ, Cui FZ, Kim TN, Kim JO. A mechanistic study of the antibacterial effect of silver ions on Escherichia coli and Staphylococcus aureus. J Biomed Mater Res. 2000;52(4):662-668.

11. Kalishwaralal K, BarathManiKanth S, Pandian SR, Deepak V, Gurunathan S. Silver nanoparticles impede the biofilm formation by Pseudomonas aeruginosa and Staphylococcus epidermidis. Colloids Surf B Biointerfaces. 2010;79(2):340-344.

12. Papageorgiou I, Brown C, Schins R, et al. The effect of nano- and micron-sized particles of cobalt-chromium alloy on human fibroblasts in vitro. Biomaterials. 2007;28(19):2946-2958.

13. Lu Y, Mei Y, Schrinner M, Ballauff M, Möller MW, Breu J. In situ formation of Ag nanoparticles in spherical polyacrylic acid brushes by UV irradiation. J Phys Chem C. 2007;111(21):7676-7681.

14. Willner I, Baron R, Willner B. Growing metal nanoparticles by enzymes. Adv Mater. 2006;18(9):1109-1120.

15. Mallikarjuna NN, Varma RS. Microwave-assisted shape-controlled bulk synthesis of noble nanocrystals and their catalytic properties. Cryst Growth Des. 2007;7(4):686-690.

16. Chen M, Wang LY, Han JT, Zhang JY, Li ZY, Qian DJ. Preparation and study of polyacryamide-stabilized silver nanoparticles through a one-pot process. J Phys Chem B. 2006;110(23):11224-11231.

17. Lou XW, Yuan C, Archer LA. An unusual example of hyperbranched metal nanocrystals and their shape evolution. Chem Mater. 2006;18(17):3921-3923.

18. Kuo PL, Chen WF. Formation of silver nanoparticles under structured amino groups in pseudo-dendritic poly(allylamine) derivatives. J Phys Chem B. 2003;107(41):11267-11272.

19. Valodkar M, Bhadoria A, Pohnerkar J, Mohan M, Thakore S. Morphology and antibacterial activity of carbohydrate-stabilized silver nanoparticles. Carbohydr Res. 2010;345(12):1767-1773.

20. Jaiswal S, Duffy B, Jaiswal AK, Stobie N, McHale P. Enhancement of the antibacterial properties of silver nanoparticles using beta-cyclodextrin as a capping agent. Int J Antimicrob Agents. 2010;36(3):280-283.

21. Fayaz AM, Balaji K, Girilal M, Yadav R, Kalaichelvan PT, Venketesan R. Biogenic synthesis of silver nanoparticles and their synergistic effect with antibiotics: a study against Gram-positive and Gram-negative bacteria. Nanomedicine. 2010;6(1):103-109.

22. Salunkhe RB, Patil SV, Salunke BK, Patil CD, Sonawane AM. Studies on silver accumulation and nanoparticle synthesis by Cochliobolus lunatus. Appl Biochem Biotechnol. 2011;165(1):221-234.

23. Shahverdi AR, Fakhimi A, Shahverdi HR, Minaian S. Synthesis and effect of silver nanoparticles on the antibacterial activity of different antibiotics against Staphylococcus aureus and Escherichia coli. Nanomedicine. 2007;3(2):168-171.

24. Wang B, Chen K, Jiang S, et al. Chitosan-mediated synthesis of gold nanoparticles on patterned poly(dimethylsiloxane) surfaces. Biomacromolecules. 2006;7(4):1203-1209.

25. Yi H, Wu LQ, Bentley WE, et al. Biofabrication with chitosan. Biomacromolecules. 2005;6(6):2881-2894.

26. Dos Santos DS Jr, Goulet PJ, Pieczonka NP, Oliveira ON Jr, Aroca RF. Gold nanoparticle embedded, self-sustained chitosan films as substrates for surface-enhanced Raman scattering. Langmuir. 2004;20(23):10273-10277.

27. Liu X, Hu Q, Fang Z, Zhang X, Zhang B. Magnetic chitosan nanocomposites: a useful recyclable tool for heavy metal ion removal. Langmuir. 2009;25(1):3-8. 
28. Duan W, Shen C, Fang H, Li GH. Synthesis of dehydroabietic acidmodified chitosan and its drug release behavior. Carbohydr Res. 2009;344(1):9-13.

29. Jin X, Wang J, Bai J. Synthesis and antimicrobial activity of the Schiff base from chitosan and citral. Carbohydr Res. 2009;344(6):825-829.

30. Prochazkova S, Vårum KM, Ostgaard K. Quantitative determination of chitosans by ninhydrin. Carbohydr Polym. 1999;38(2):115-122.

31. Gui J, Song Y, Han NL, Sheu FS. Characterization of transcriptional regulation of neurogranin by nitric oxide and the role of neurogranin in SNP-induced cell death: implication of neurogranin in an increased neuronal susceptibility to oxidative stress. Int $J$ Biol Sci. 2007;3(4):212-224.

32. Neumeyer A, Bukowski M, Veith M, Lehr CM, Daum N. Propidium iodide labeling of nanoparticles as a novel tool for the quantification of cellular binding and uptake. Nanomedicine. 2011;7(4):410-419.

33. Sonawane A, Santos JC, Mishra BB, et al. Cathelicidin is involved in the intracellular killing of mycobacteria in macrophages. Cell Microbiol. 2011;13(10):1601-1617.

34. Liu N, Chen XG, Park HJ, et al. Effect of MW and concentration of chitosan on antibacterial activity of Escherichia coli. Carbohydr Polym. 2006;64(1):60-65.

35. Chung YC, Wang HL, Chen YM, Li SL. Effect of abiotic factors on the antibacterial activity of chitosan against waterborne pathogens. Bioresour Technol. 2003;88(3):179-184.

36. Varma AJ, Deshpande SV, Kennedy JF. Metal complexation by chitosan and its derivatives: a review. Carbohydr Polym. 2004;55(1):77-93.

37. Murugadoss A, Chattopadhyay A. A 'green' chitosan-silver nanoparticle composite as a heterogeneous as well as micro-heterogeneous catalyst. Nanotechnology. 2008;19(1):015603.
38. Basu S, Jana S, Pande S, Pal T. Interaction of DNA bases with silver nanoparticles: assembly quantified through SPRS and SERS. J Colloid Interface Sci. 2008;321(2):288-293.

39. Hauck TS, Ghazani AA, Chan WC. Assessing the effect of surface chemistry on gold nanorod uptake, toxicity, and gene expression in mammalian cells. Small. 2008;4(1):153-159.

40. Khan JA, Pillai B, Das TK, Singh Y, Maiti S. Molecular effects of uptake of gold nanoparticles in HeLa cells. Chembiochem. 2007;8(11):1237-1240.

41. Pan Y, Neuss S, Leifert A, et al. Size-dependent cytotoxicity of gold nanoparticles. Small. 2007;3(11):1941-1949.

42. Yen HJ, Hsu SH, Tsai CL. Cytotoxicity and immunological response of gold and silver nanoparticles of different sizes. Small. 2009;5(13):1553-1561.

43. AshaRani PV, Low Kah Mun G, Hande MP, Valiyaveettil S. Cytotoxicity and genotoxicity of silver nanoparticles in human cells. ACS Nano. 2009;3(2):279-290.

44. Pernodet N, Fang X, Sun Y, et al. Adverse effects of citrate/gold nanoparticles on human dermal fibroblasts. Small. 2006;2(6) 766-773.

45. Yang H, Liu C, Yang D, Zhang H, Xi Z. Comparative study of cytotoxicity, oxidative stress and genotoxicity induced by four typical nanomaterials: the role of particle size, shape and composition. $J \mathrm{Appl}$ Toxicol. 2009;29(1):69-78.

46. Desjardins M, Griffiths G. Phagocytosis: latex leads the way. Curr Opin Cell Biol. 2003;15(4):498-503.

47. Jann NJ, Schmaler M, Kristian SA, et al. Neutrophil antimicrobial defense against Staphylococcus aureus is mediated by phagolysosomal but not extracellular trap-associated cathelicidin. J Leukoc Biol. 2009;86(5):1159-1169. 


\section{Supplementary figures}

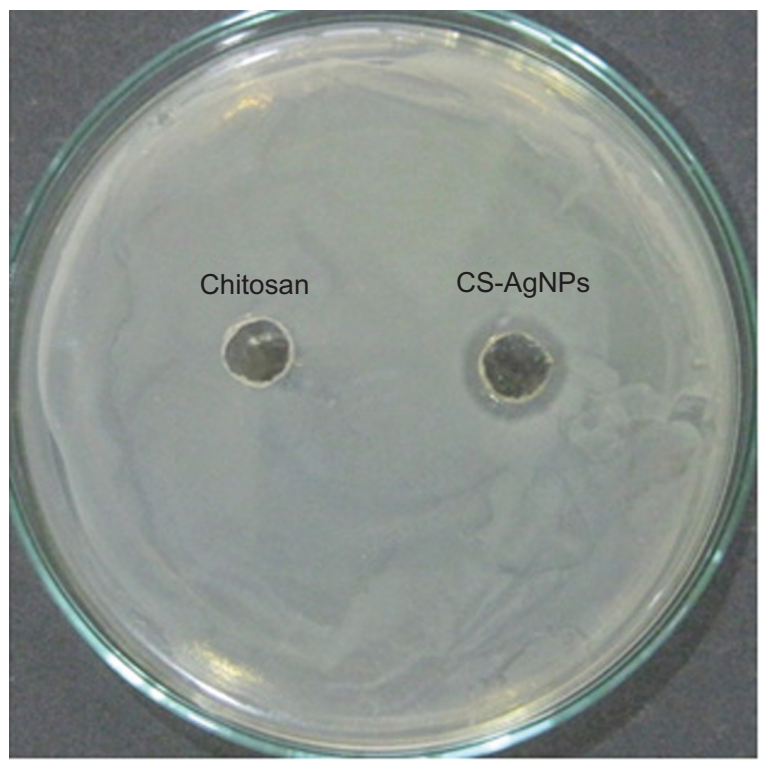

Figure SI Antibacterial activity of silver nanoparticles (AgNPs) by agar diffusion method: chitosan-stabilized AgNPs (CS-AgNPs) at 2 pPm were loaded into the wells formed on plates containing a lawn of Staphylococcus aureus; growth inhibition was determined by measuring the zone of inhibition after 24 hours; chitosan was used as a control.
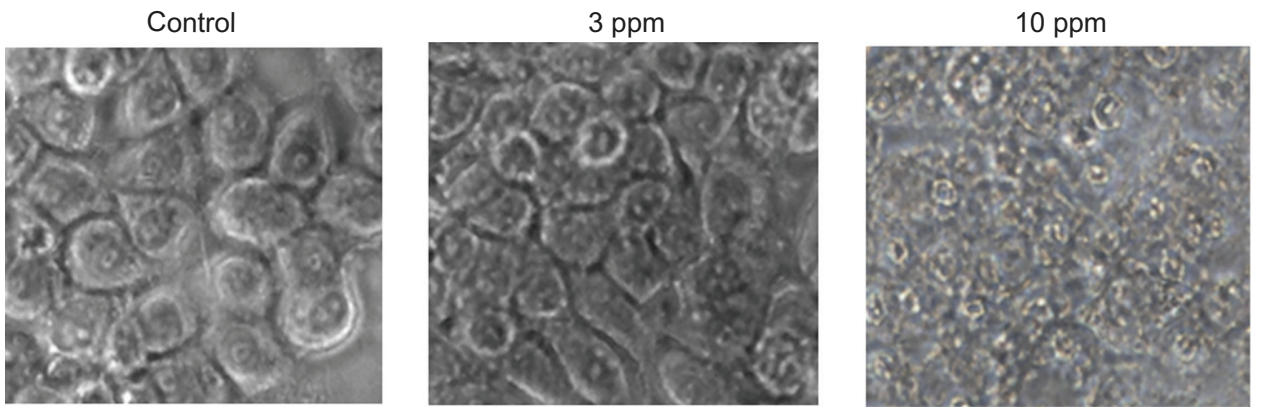

Figure S2 Cytotoxicity of chitosan-stabilized silver nanoparticles (CS-AgNPs) on mouse macrophage RAW264.7 cells. Cell morphology of RAW264.7 macrophages after treatment with different concentrations ( 3 and 10 ppm) of CS-AgNPs for 24 hours. Cells grown in medium and chitosan were used as a control.

\section{Publish your work in this journal}

The International Journal of Nanomedicine is an international, peerreviewed journal focusing on the application of nanotechnology in diagnostics, therapeutics, and drug delivery systems throughout the biomedical field. This journal is indexed on PubMed Central, MedLine, CAS, SciSearch ${ }^{\circledR}$, Current Contents ${ }^{\circledR} /$ Clinical Medicine,
Journal Citation Reports/Science Edition, EMBase, Scopus and the Elsevier Bibliographic databases. The manuscript management system is completely online and includes a very quick and fair peer-review system, which is all easy to use. Visit http://www.dovepress.com/ testimonials.php to read real quotes from published authors. 